\title{
Anatomy and Its Variations for Endoscopic Sinus Surgery
}

\author{
Ashok K Gupta, Sandeep Bansal, Daisy Sahini
}

\begin{abstract}
There has been a major advancement in managing chronic sinusitis and other sinonasal diseases. There has been a remarkable change in the surgical approach to inflammatory pathology of paranasal sinuses since the time, Messerklinger introduced endoscopic sinus surgery. In this changing scenario of indications for endoscopic sinus surgeries, detailed knowledge of sinonasal anatomy is of paramount importance. It is of utmost importance to master the relevant anatomy and its variations before one embarks upon endoscopic sinus surgery. Various cadaveric and radiological studies have been done to know about the important landmarks and anatomical variations. With increasing horizon of sinus surgery, where more of optic nerve and anterior and middle cranial fossa lesions are being dealt with endoscopically; surgeon needs to be more familiar with various variations in the anatomy of the important structures as even a small mistake can be detrimental to the vision and life of the patient.
\end{abstract}

Keywords: Anatomy, Endoscopic sinus surgery, Cadaveric dissection, Anatomical variations.

How to cite this article: Gupta AK, Bansal S, Sahini D. Anatomy and Its Variations for Endoscopic Sinus Surgery. Clin R hinol An Int J 2012;5(2):55-62.

\section{Source of support: $\mathrm{Nil}$}

Conflict of interest: None declared

\section{INTRODUCTION}

'If the ethmoid were placed in any other part of the body, it would be an insignificant and harmless collection of bony cells. In the place where nature has put it, it has major relationships so that diseases and surgery of the labyrinth often leads to tragedy. A ny surgery in this region should be simple but has proven one of the easiest ways to kill a patient'.

Mosher $1929^{1}$

There has been a major advancement in managing chronic sinusitis and other sinonasal diseases. There has been a remarkable change in the surgical approach to inflammatory pathology of paranasal sinuses since the time, M esserklinger introduced endoscopic sinus surgery. In this changing scenario of indications for endoscopic sinus surgeries; detailed knowledge of sinonasal anatomy is of paramount importance. It is of utmost importance to master the relevant anatomy and its variations before one embarks upon endoscopic sinus surgery. Various cadaveric and radiological studies have been done to know about the important landmarks and anatomical variations. Rontal and Rontal reported the anatomical relationships and the critical landmarks for endoscopic sinus surgery. ${ }^{2}$ Becker analyzed serial sections of frozen cadaver heads in axial, coronal and sagittal planes to understand the anatomy of the paranasal sinuses. ${ }^{3}$ Sahni et al have reported the variations in sinonasal anatomy in North Indian population. ${ }^{4}$

Radiological investigations and image-guided systems are also important tools which help to perform a safe and successful surgery though can in no way replace surgeon's thorough anatomical knowledge. Llyod et al in 1991 reported the usefulness of computed tomography (CT) in preoperative eval uation before functional endoscopic sinus surgery (FESS). High resolution CT scanning of nose and paranasal sinus (PNS) provides excellent bony detail and soft tissue mapping. A xial and coronal views are obtained with the head in neutral position and hyperextension respectively. ${ }^{5}$ CT has become the modality of choice for inflammatory disease of the sinuses especially the ostiomeatal complex. Limited resections of inflammatory tissue or anatomic obstruction along with normal drainage channels of the sinuses reestablish mucociliary clearance of the sinuses. High resolution CT evaluates the extent of the inflammatory disease and assesses important anatomic landmarks and their variations.

PNS CT has become a widely accepted tool for providing detailed anatomy of PNS. To avoid complications during endoscopic sinus surgery, CT scan should be studied thoroughly before surgery.

Scan protocol should include:

- Slice thickness $3 \mathrm{~mm}$

- Scans to be taken in all three planes-axial, coronal and sagittal

- B oth soft tissue and bone windows to be studied.

A natomy of the sinonasal passages have many variations; some of which are seen more frequently in patients with chronic sinonasal inflammation. The anatomical variations can result in narrowing of the infundibulum or the maxillary ostium. Presence of O nodi cells, low placed fovea ethmoidalis are some 'dangerous' normal variations that should be recognized before FESS to avoid risk of injury.

A natomical variations commonly seen included deviated nasal septum (DNS), inferior turbinate hypertrophy (ITH), concha bullosa, paradoxical and duplicated middle turbinate $(M T)$, fenestrated uncinate process (UP), maxillary septa and hypoplasia, types of frontal cell, type of olfactory fossa, onodi cells and type of optic nerve. Some of the parameters, like septal pneumatization, pneumatized crista galli, clinoid process and pterygoid pneumatization can be studied only radiologically. 
The preoperative understanding of these anatomical variations is the key for a safe endoscopic sinus surgery procedure. $^{6,7}$

\section{Osteomeatal Unit}

- It refers to the common drainage pathw ay of the anterior sinuses (frontal, maxillary, anterior and middle ethmoid sinuses). The ostiomeatal unit in the center of interest in the lateral wall of the nose since the development of FESS, since it is thought to be the key in the pathogenesis of chronic sinusitis.

- OMU is comprised of:

- Ethmoid infundibulum

- Uncinate process

- Ethmoid bulla

- Hiatus semilunaris

- Middle meatus.

\section{Nasal Septum}

Commonest variation seen is a DNS (Figs $1 \mathrm{~A}$ to $\mathrm{C}$ ).

$V$ ariations like septal pneumatization can be picked up only on CT scan of nose and paranasal sinuses (Fig. 1D).

\section{Inferior Turbinate}

Inferior turbinate hypertrophy (ITH) can be a compensatory process or an infectious pathology. A preoperative preparation with steroid nasal spray and decongestants helps to reduce the inflammation. Inferior turbinate pneumatization is very rare ${ }^{8}$ and, if present, will grossly obstruct the nasal airway.

\section{MIDDLE TURBINATE AND MIDDLE MEATUS}

Middle turbinate (ethmoid bone) overlying the middle meatus is the most important anatomic area in the lateral wall of the nose. Superiorly, it is attached to lateral aspect

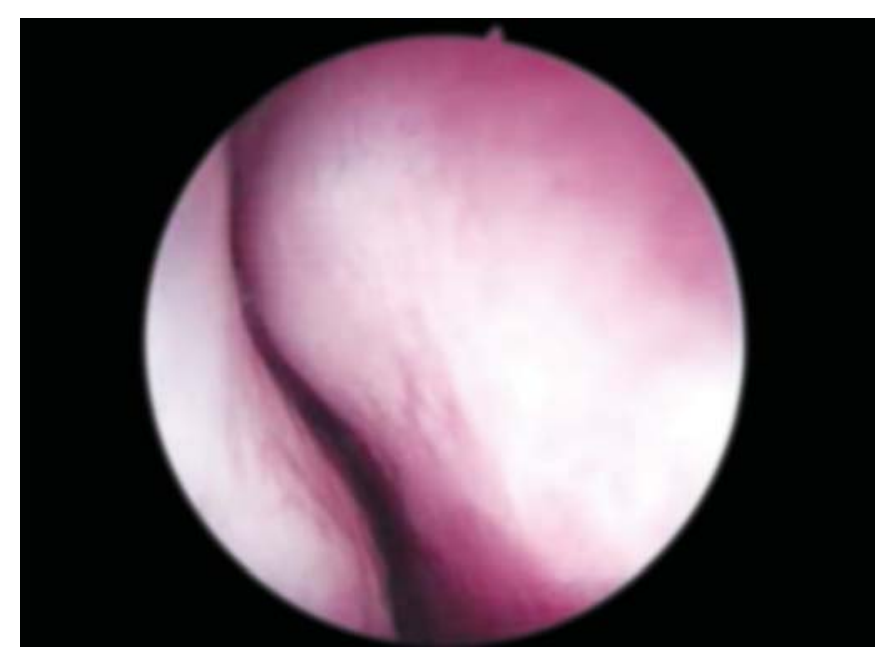

Fig. 1A: Endoscopic picture showing a deviated nasal septum

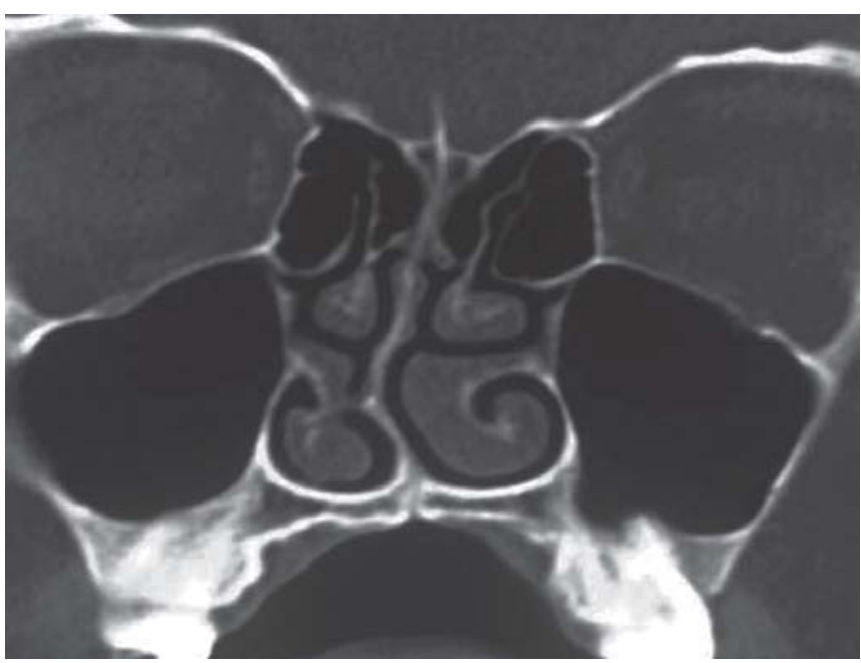

Fig. 1B: CT scan (coronal cut) showing a deviated nasal septum

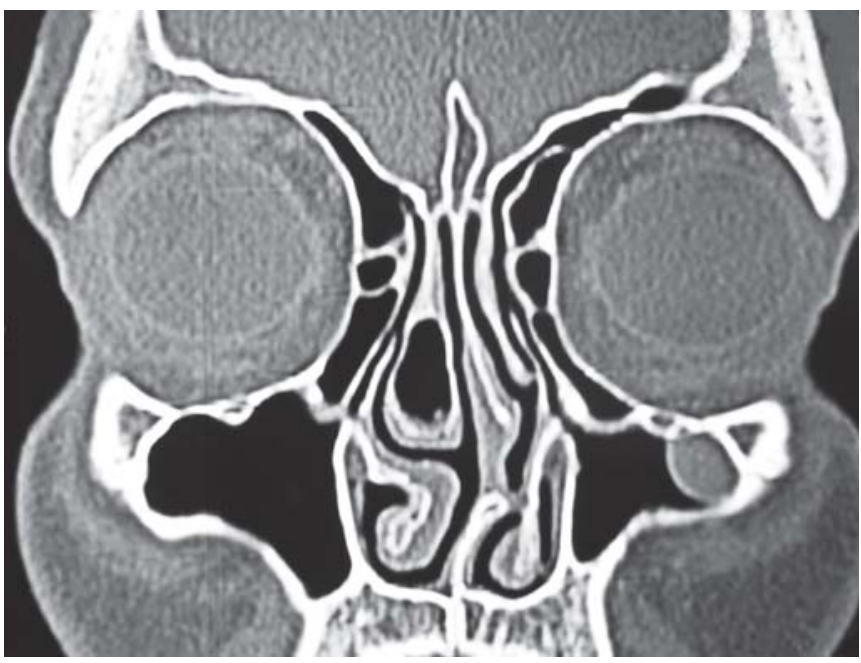

Fig. 1C: CT scan (coronal cut) showing a deviated nasal septum and a concha bullosa on the opposite side

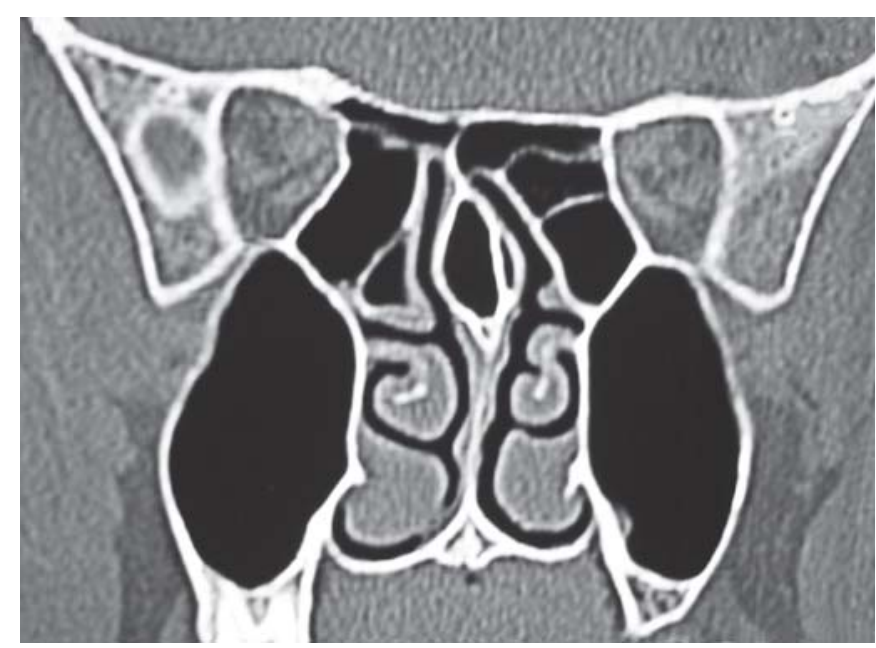

Fig. 1D: CT scan coronal cut showing septal pneumatization

of the cribriform plate; between cribriform plate and fovea ethmoidalis. Its lateral attachment, called the basal lamella, attaches to the thin lamina papyracea of the lateral ethmoidal wall. Posteriorly, the basal lamella curves superiorly to 
become coronally orientated. This coronal part separates the anterior from the posterior ethmoidal air cells (Table 1).

\section{Table 1: Orientation and attachments of middle turbinate}

\begin{tabular}{lll} 
Site & Direction & Attachment \\
\hline Anterior $1 / 3$ rd & Vertical & Skull base \\
Middle $1 / 3$ rd & Oblique & Lamina papyracea \\
Posterior $1 / 3$ rd & Transverse & Perpendicular plate of palatine bone
\end{tabular}

\section{Drainage to the Middle Meatus}

1. Bulla ethmoidalis: A prominent anterior ethmoid air cell, located posteriorly in the middle meatus. Receives drainage from anterior group of ethmoid air cells and drain into ethmoid infundibulum/middle meatus.

2. Hiatus semilunaris: Just inferior to bulla ethmoidalis. A nteriorly, it receives drainage from anterior ethmoidal air cells. Posteriorly, it receives drainage of the maxillary sinus via the maxillary sinus ostium.

3. F rontal recess/nasofrontal duct: Defined as bony walls that lead to and communicate with frontal sinus. Frontal sinus drains via frontal recess and nasofrontal duct into middle meatus.

Pneumatization of the middle turbinate occurs as a normal variant and is called concha bullosa. Concha bullosa is abnormal pneumatization of middle turbinate which may block the infundibulum and may lead to sinus disease due to defective aeration of the sinuses (Figs 2 and 3 ).

Paradoxical middle turbinate is the abnormal curvature of $M T$, where the convex surface faces laterally and may block the drainage pathw ay of middle meatus (Fig. 4). Other variations of M T which were recorded intraoperatively by Gupta et al were duplicate MT in two $(1.44 \%)$; multilobulated MT in one $(0.72 \%)$; accessory M T in one $(0.72 \%)$ and bifid M T in one $(0.72 \%)$ case. $^{9}$

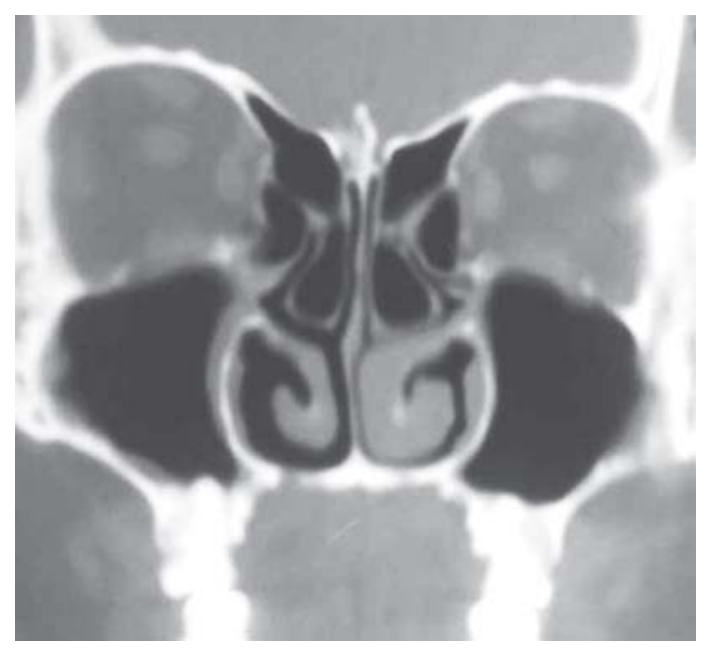

Fig. 2: Bilateral concha bullosa

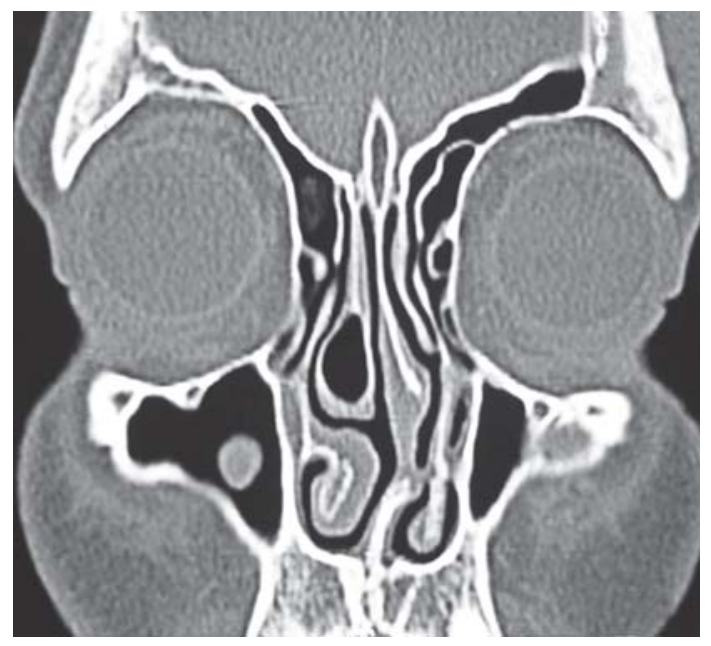

Fig. 3: Septal spur with concha bullosa

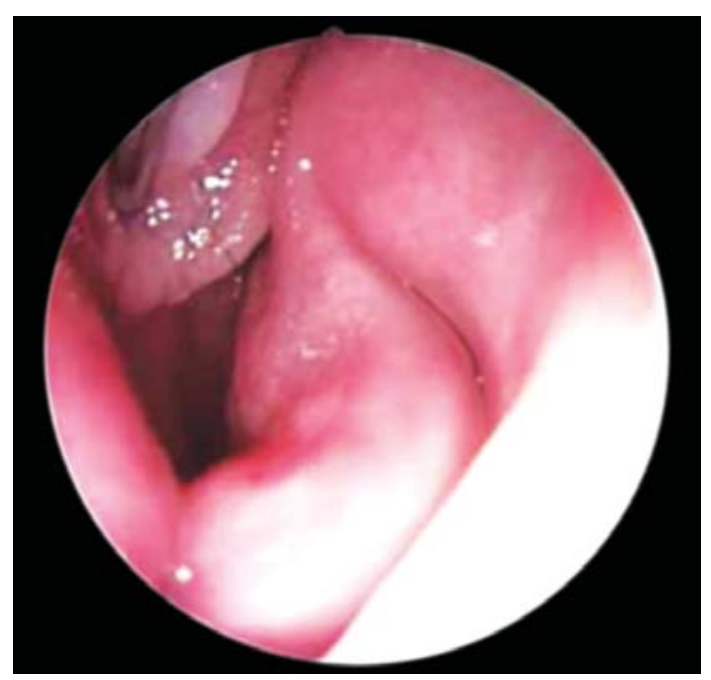

Fig. 4: Endoscopic picture showing paradoxical middle turbinate

\section{Superior Turbinate}

It is the smallest turbinate which overlies the superior meatus. Posterior ethmoidal air cells drain into superior meatus via multiple ostia. Sphenoethmoidal recess lies on posterosuperior aspect of superior turbinate between the anterior wall of the sphenoid sinus and the posterior wall of the ethmoid air cells. Sphenoethmoidal recess drains the sphenoid sinus through the sphenoid ostium.

\section{Ethmoidal Infundibulum}

It is cleft like 3D space in the lateral wall of the nose bounded medially by the uncinate process, laterally by the lamina papyracea and frontal process of maxilla and posteriorly by the anterior surface of the ethmoidal bulla. It becomes atelectatic, if there is paradoxical middle turbinate, concha bullosa or if the uncinate process is butting against the lamina papyracea. 


\section{Uncinate Process}

It is a thin, sickle or L-shaped bone resembling a bent hook or a boomerang. Its ascending convex anterior margin merges with the lateral nasal wall, whereas the posterior margin is sharp, free and concave.

A ttachment of uncinate process is known to have a bearing on the drainage of frontal sinus. If it is attached to lamina papyracea, frontal sinus drains medial to UP but, if it is attached to skull base or $M T$, then sinus drains into infundibulum just lateral to UP. One should be aware of presence of accessory ostium because during surgery, if the natural and accessory ostia are not joined then it can lead to recirculation phenomenon with persistent symptoms (Fig. 5).
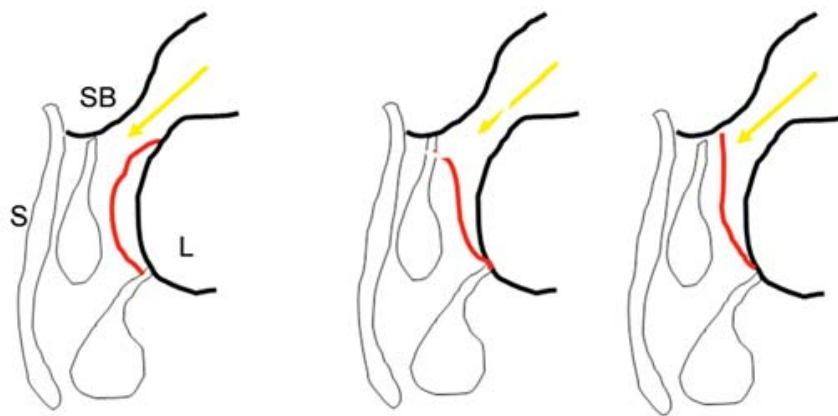

Fig. 5: The different drainage patterns of frontal sinus based on the attachment of uncinate process (S: Septum; SB: Skull base; L: Lamina papyracea)

\section{Agger Nasi Cells}

A gger nasi cells are the anterior most anterior ethmoid air cells located anterior and inferior to frontal recess draining into the ethmoid infundibulum. They act as excellent surgical landmarks for frontal recess. A gger nasi cells may narrow the frontal recess and obstruct the lower end of the frontonasal duct leading to frontal sinus disease. There may be extension of pneumatization of anterior ethmoid air cells into frontal process of the maxilla/lacrimal bone.

\section{Ethmoidal Bulla}

It is the most constant anterior ethmoid air cell forming the posterior border of hiatus semilunaris. Its lateral extent is the lamina papyracea and superiorly extends up to the ethmoid roof.

\section{Hiatus Semilunaris Inferior}

It is crescent-shaped cleft, located between posterior free margin of the uncinate process and the corresponding anterior face of the ethmoidal bulla of variable dimensions. It is a cleft like door through which ethmoidal infundibulum communicates with the midlle meatus.

\section{Hiatus Semilunaris Superior}

This is also a crescent-shaped cleft between basal lamella and the posterior wall of bulla ethmoidalis. It is through this gap that the sinus lateralis, when present (retrobullar and suprabullar recesses) can be entered inferomedially underneath the middle turbinate.

\section{LATERAL SINUS (SINUS LATERALIS OF GRUNWALD)}

It is bounded:

- Laterally-lamina papyracea

- Superiorly- ethmoid roof

- Posteriorly-ground lamella

- A nterior and inferior- roof and posterior wall of ethmoids.

\section{Anterior Ethmoidal Artery}

A nterior ethmoidal artery (AEA) is located in roof of anterior ethmoids posterior to frontal recess and may lie in a bony canal or in a bony mesentry. It can be visualized on coronal sections on CT scan where it forms medial beak of superomedial orbital wall as it branches out from ophthalmic artery (Figs $6 \mathrm{~A}$ and $\mathrm{B}$ ).
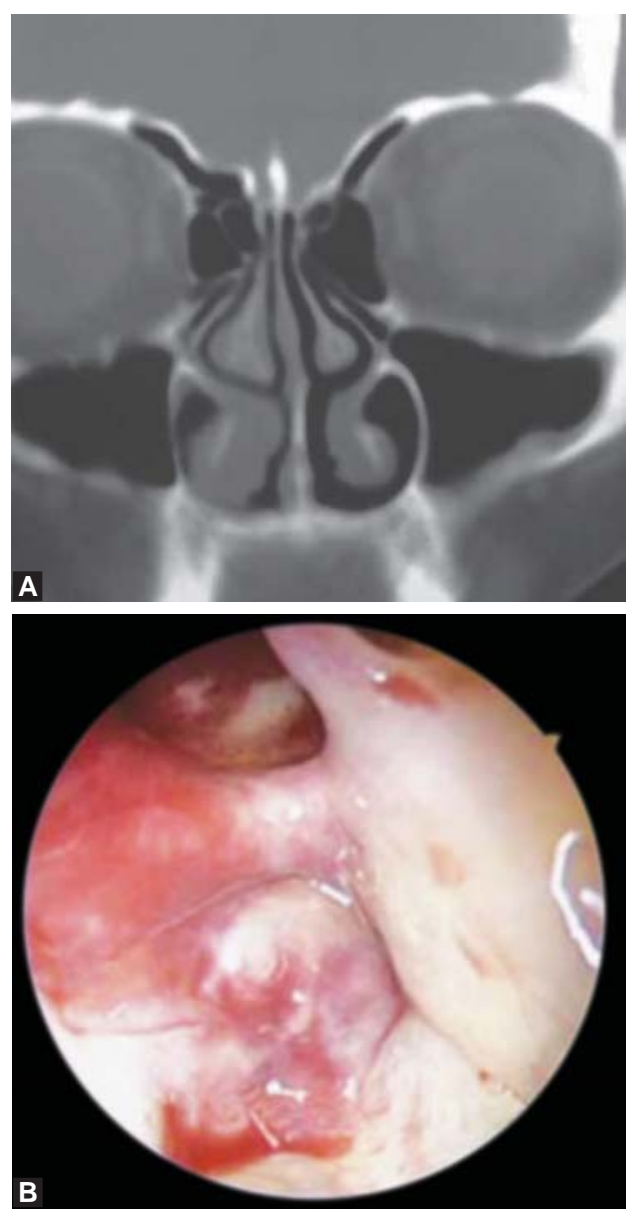

Figs 6A and $B:(A) A E A$ as a beak of superomedial orbital wall on $C T$ scan, $(B)$ endoscopic picture showing $A E A$ 


\section{SURGICAL SIGNIFICANCE}

The weakest point of the entire skull base is the point at which the AEA leaves the ethmoid and proceeds anteriorly in the ethmoidal sulcus of the olfactory fossa. G reatest caution must be exercised while working medial to the ethmoid roof.

$K$ nowledge of course of $A E A$ is very important for surgeon. If injured during surgery, it gets retracted into the orbit causing orbital hematoma and subsequent visual loss if not treated immediately. So, surgeon must be familiar with the possibility of an abnormal course of AEA.

\section{IDENTIFICATION}

- Follow the anterior surface of the bulla in the direction of the roof, the artery is 1 to $2 \mathrm{~mm}$ posterior to their confluence.

- If the anterior bulla lamina does not extend up to the roof and there is no separation between the frontal recess and lateral sinus, the artery is seen in the lateral sinus.

\section{Haller Cells (Infraorbital Ethmoid Air Cell)}

Haller cells develop in the floor of the orbit, adjacent and above the maxillary ostium.

When enlarged constrict the infundibulum and blocks the maxillary sinus ostium.

\section{Olfactory Fossa}

- Frontal bone lamellae are much thicker than ethmoid lamellae.

- Frontal bone abuts against the lateral lamella of lamina cribrosa, constituting the lateral border of olfactory fossa which can vary.

Highest point of the roof of the ethmoid can be as much as $17 \mathrm{~mm}$ higher than the lamina cribrosa.

Kero's has described three type of olfactory fossa depending on the depth; type I: 1 to $3 \mathrm{~mm}$; type II: 4 to $7 \mathrm{~mm}$ and type III: $>8 \mathrm{~mm} .{ }^{10} \mathrm{M}$ ore is the depth; more are the chances of injury to skull base during endoscopic sinus surgery (Figs $7 \mathrm{~A}$ to $\mathrm{C}$ ).
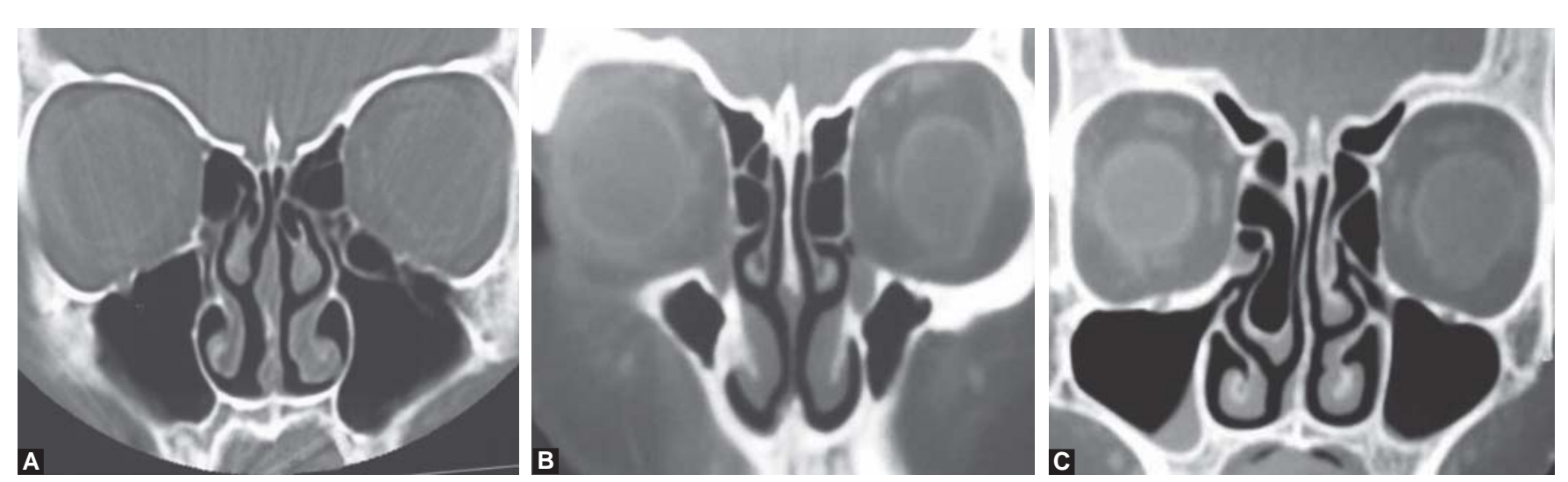

Figs 7A to C: The Kero's types 1, 2 and 3 type of olfactory fossa on CT scan: (A) type 1, (B) type 2 and (C) type 3
The lateral lamella is particularly vulnerable, where the olfactory fossa is deep the cribriform plate. A nterior cranial perforation with CSF leak may occur, if the surgeon is not aware of low ethmoid roof or excessive sloping of the roof.

The posterior ethmoid cells may extend into sphenoid sinus and may surround the optic nerve. These cells are called onodi cells. Their presence may increase the chances of optic nerve injury (Fig. 8).

\section{Surgical Importance}

Posterior cells can develop laterally or superiorly (onodi cell) over the sphenoid sinus. L aterally, these may lie up to $1.5 \mathrm{~cm}$ beyond the sphenoid sinus. In the presence of an onodi cell, the anterior wall of sphenoid runs from anteromedial to posterolateral instead of frontally, so the direction of dissection must always be inferomedial after perforaton of the ground lamella.

Daisy $\mathrm{S}$ et al reported onodi cells in $10 \%$ of cadavers. ${ }^{3}$ Generally, in presence of onodi cell optic nerve passes through the cell but not always as reported by Gupta et al. A preoperative knowledge of attachment of sphenoid septa

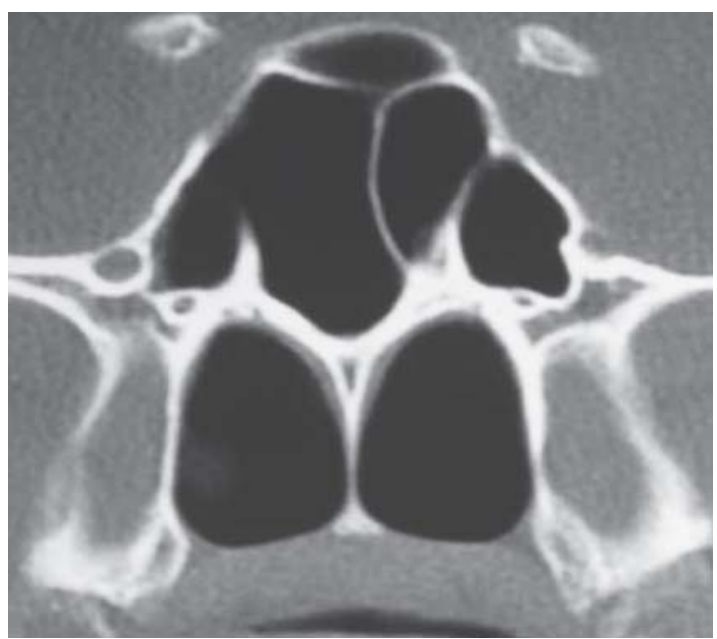

Fig. 8: CT scan (coronal cut) showing the onodi cell

\section{Onodi Cell}


can reduce complications as they can be attached to optic nerve or carotid artery. In a study by Gupta et al, 3\% of intrasphenoid septa were found to be attached to optic nerve and $2 \%$ were found to be attached to carotid artery. ${ }^{9}$

\section{Sphenoid Sinus}

It is the most posterior of the paranasal sinuses lying superior to nasopharynx, anterior and inferior sella having variable pneumatization with inverse relationship between pneumatization and the thickness of the sinus wall.

A ccording to Congdon, ${ }^{11}$ sphenoid pneumatization (Figs 9A to C) can be as follows:

- A: Conchal-5\%

- B: Presellar-23\%

- C: Postsellar-67\%

A nterior face of the sphenoid lies approximately $7 \mathrm{~cm}$ from nasal sill on $30^{\circ}$ axis from the horizontal.

\section{Relationships of Important Structures}

- Superior: Hypophysis, olfactory tract, frontal lobe

- Inferior: Nasopharynx, vidian nerve

- Lateral: Cavernous sinus, carotid, cranial nerves 2, 3, $4,5,6$.

- Posterior: Pons, basilar artery (Fig. 10)

\section{Sphenoid Sinus Variations}

\section{Optic Nerve}

Delano, Fun and Zinreich classification ${ }^{12}$

\begin{tabular}{cl}
\hline Type & Description \\
\hline 1 & Adjacent to sphenoid sinus (Figs 11 and 12) \\
2 & Indentation on sphenoid sinus (see Figs 11 and 12) \\
3 & Optic nerve traversing sphenoid sinus \\
4 & Adjacent to sphenoid and posterior ethmoid sinuses \\
\hline
\end{tabular}

There may be multiseptate sphenoid sinus (Figs 13A and B). Complete clearance of disease from all compartments is a must to prevent residual disease. There may be excessive pneumatization of the pterygoid processes (Fig. 14). Dehiscent carotid artery was seen in $10.2 \%$ sides and dehiscent optic nerve in $18.2 \%$ by B enjaporn Nitinavakarn et al ${ }^{13}$ and 6 and $4 \%$ respectively in a study by Josef Kainz et al. ${ }^{14} \mathrm{~A}$ study by Sheetal et al noticed dehiscence in both structures in $2 \%$ cases $^{15}$ comparable to the study by Gupta et al who reported dehiscence of both in $2.89 \%$ cases. Dehiscent carotid artery and optic nerve increase the chances of complications during surgery. ${ }^{9}$

\section{Frontal Sinus}

Frontal sinus develops from small grooves in the cartilage of the lateral nasal wall during the third and fourth fetal

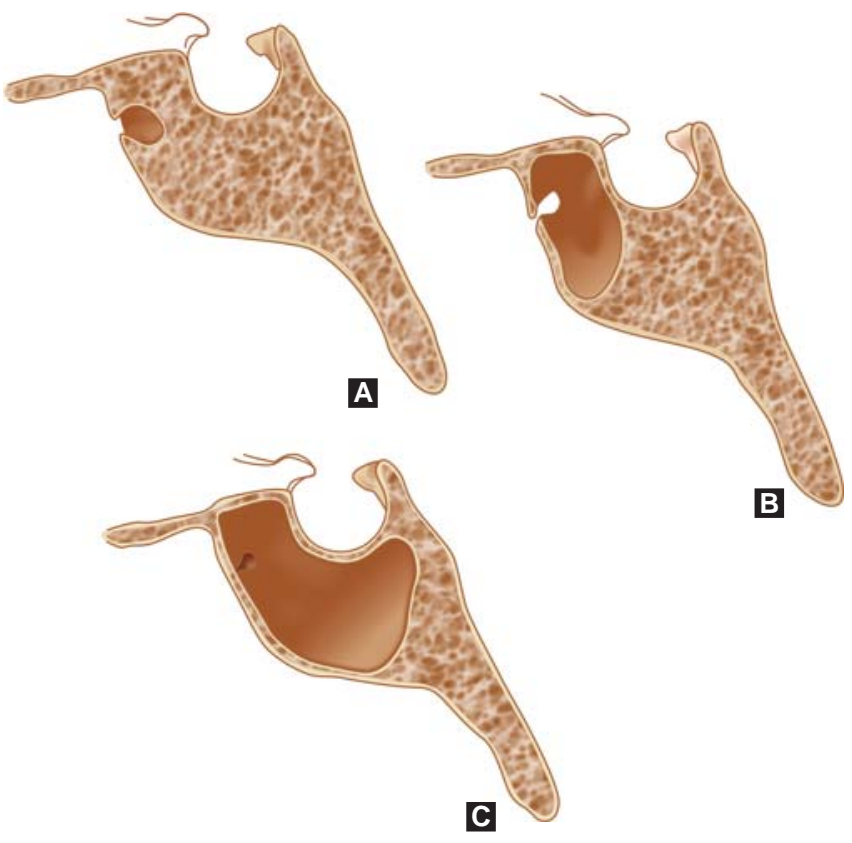

Figs 9A to C: The sphenoid pneumatization: $(A)$ conchal, (B) presellar, (C) postsellar ${ }^{11}$

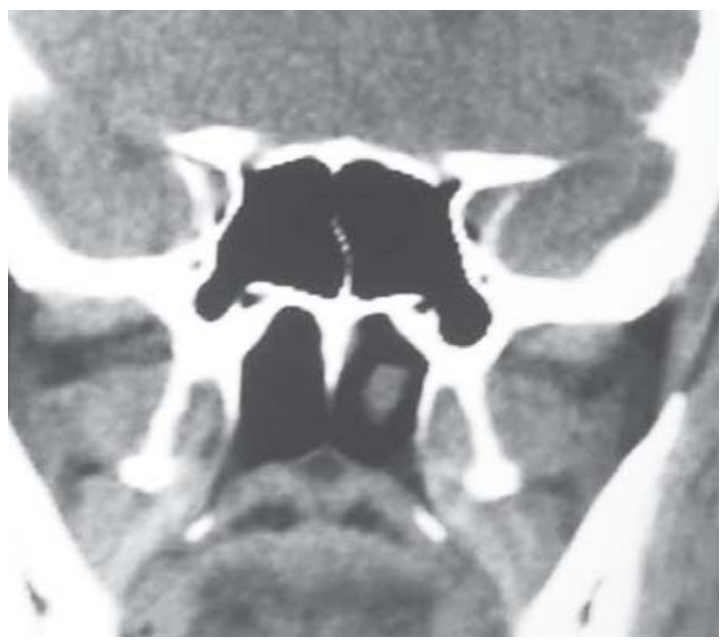

Fig. 10: The anterior clenoid process, optic canals, vidian nerve and pneumatization of pterygoid process

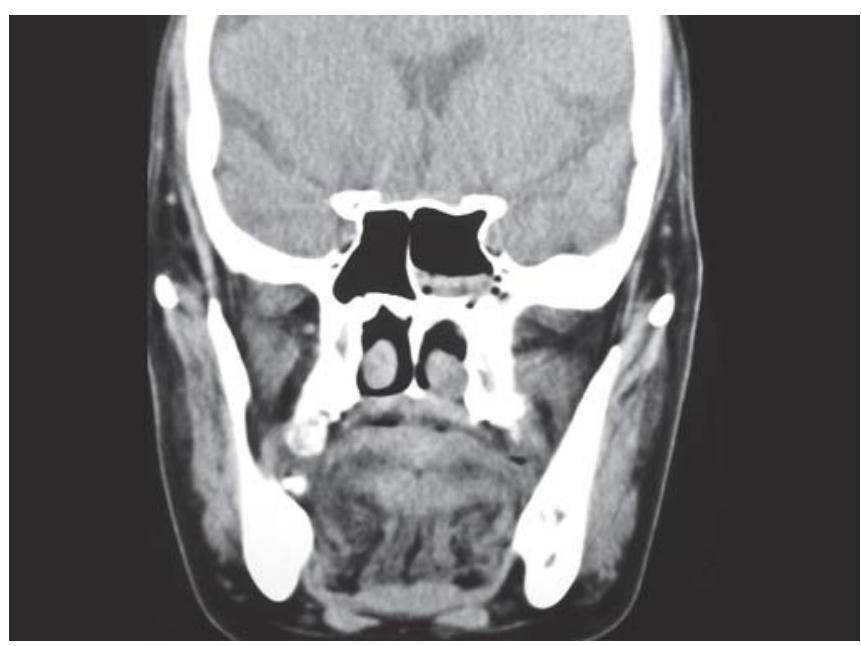

Fig. 11: CT scan showing type 1 optic nerve on the right and type 2 on the left side 


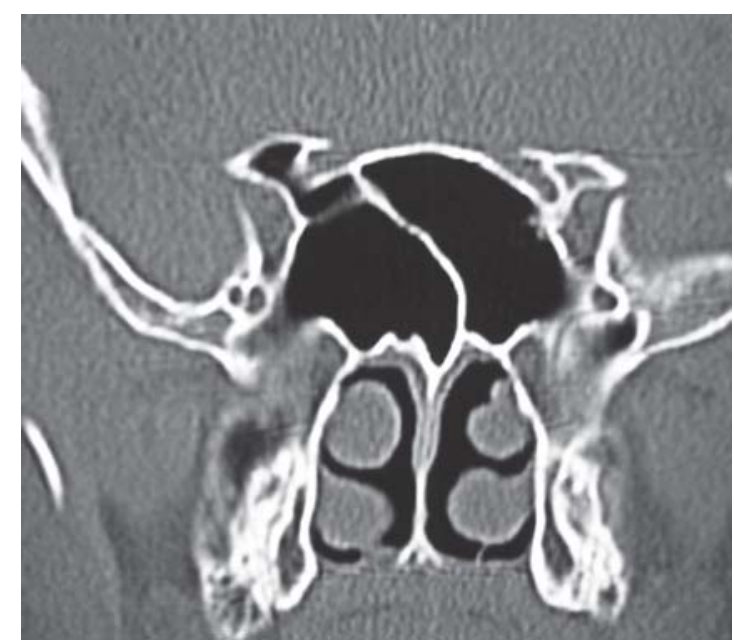

Fig. 12: CT scan showing type 2 optic nerve on the right side
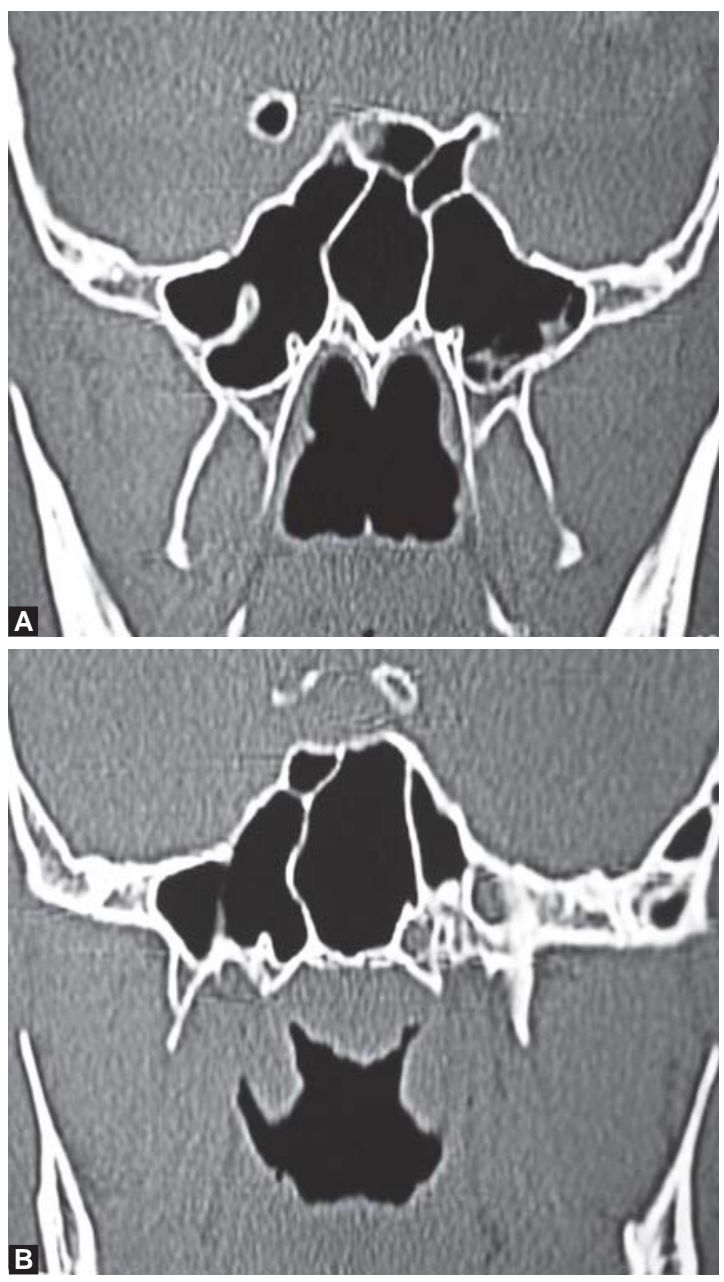

Figs 13A and B: Multiple septa in sphenoid sinus

month and is incompletely developed at birth. It is first visible radiographically in patients aged 6 years. The frontal sinus opens into the frontal recess or directly into the anterior end of the infundibulum.

\section{Anatomic Boundaries of Frontal Recess}

- Anterior- unicate process and agger nasi

- Posterior- bulla ethmoidalis and suprabullar lamella

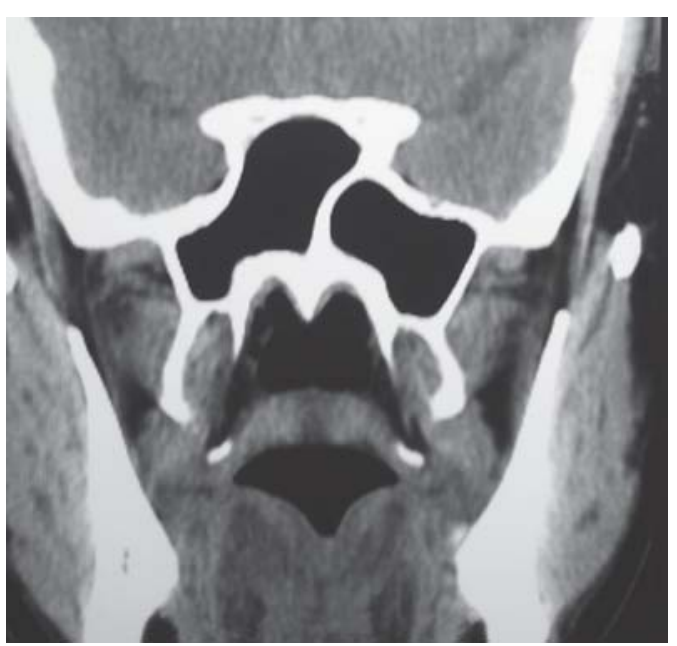

Fig. 14: CT scan showing pterygoid pneumatization of the sphenoid sinus

- Lateral-lamina papyracea

- M edially- hiatus semilunaris or middle turbinate

- Inferior-ethmoid infundibulum

- Superior-fovea ethmoidalis, supraorbital cell, AEA and frontal ostium.

\section{Frontal Cells}

Presence of various types of frontal cells (K uhn cells) may change the drainage pathway of frontal sinus. ${ }^{16}$ They should be studied in detail on CT scan preoperatively and all cells must be opened during surgery to achieve an adequate frontal sinusotomy and for complete removal of disease. The K uhn classification of frontoethmoid cells: ${ }^{16}$

- Kuhn type 1 ( $\mathrm{K} 1$ cell): Single cell above an agger nasi cell

- Kuhn type 2 (K2 cell): Two or more cells above and directly behind an agger nasi cell

- Kuhn type 3 ( $\mathrm{K} 3$ cell): Single large cell above an agger nasi cell, pneumatized into the frontal sinus $(<50 \%$ the height of the frontal sinus)

- Kuhn type 4 (K 4 cell): Single large cell above an agger nasi cell.

Pneumatized into the frontal sinus ( $>50 \%$ the height of the frontal sinus) (Figs 15A to D).

Modified K uhn classification of frontal ethmoidal cells: ${ }^{17-19}$

- Agger nasi cell

- Supraorbital ethmoid cells

- Frontoethmoidal cells

- Type 1: Single frontal recess cell above agger nasi cell

- Type 2: Tier of cells in frontal recess above agger nasi cell

- Type 3: Single massive cell pneumatizing cephalad into frontal sinus 


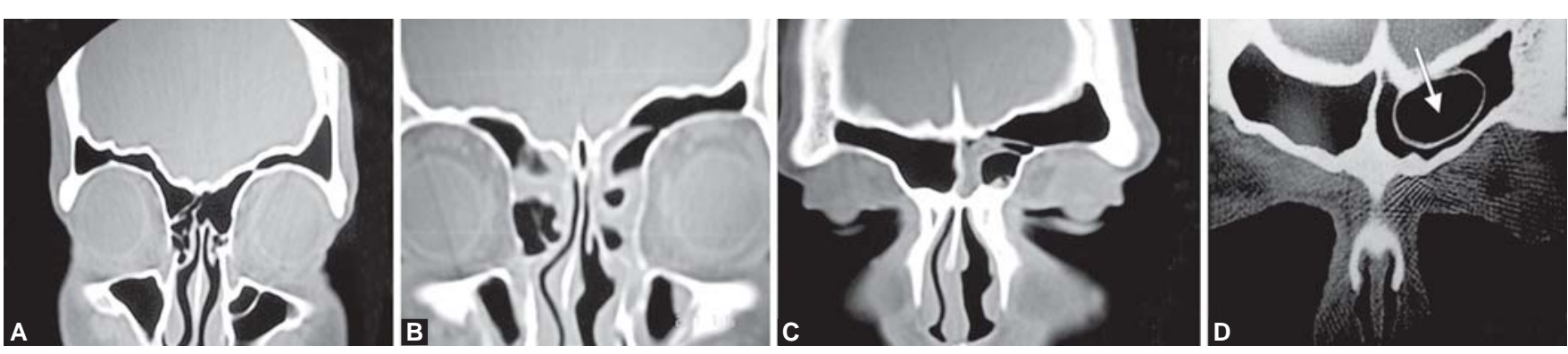

Figs 15A to D: CT scans showing the Kuhn classification of frontoethmoid cells: (A) type 1, (B) type 2, (C) type 3, (D) type 4

- Type 4: Modified from original classification A cell pneumatizing through into the frontal sinus and extending $>50 \%$ of the vertical height of the frontal sinus ${ }^{7,8}$

- Frontal bulla cells

- Supra bulla cells

- Interfrontal sinus septal cell or intersinus septal cell.

With increasing horizon of sinus surgery where more of optic nerve and anterior and middle cranial fossa lesions are being dealt with endoscopically surgeon needs to be more familiar with various variations in the anatomy of the important structures as even a small mistake can be detrimental to the vision and life of the patient. So, an in depth and thorough knowledge of the anatomy with its variations is essential for endoscopic sinus surgery and the best way for this is cadaver dissection training and attending endoscopic sinus surgery workshops.

\section{REFERENCES}

1. M osher HP. Surgical anatomy of ethmoidal labyrinth. A nn Otol Rhinol L aryngol 1929;38:869-901.

2. Rontal M, Rontal E. Studying the whole mounted sections of the paranasal sinuses to understand the complications of endoscopic sinus surgery. L aryngoscope 1991;101:361-66.

3. Becker SP. Applied anatomy of the paranasal sinuses with emphasis on endoscopic surgery. Ann Otol Rhinol Laryngol Suppl 1994;162:3-32.

4. Sahni D, M ehta R, A ggrawal A, Gupta AK. Towards the understanding of sinonasal anatomical variations: A cadaveric study. Clinical Rhinology: An International Journal 2009;2: 37-42.

5. L loyd GA S, L und V J, Scadding GK. Computerised tomography in the preoperative evaluation of functional endoscopic sinus surgery. J Laryngol Otol 1991;105:181-85.

6. Stammberger $\mathrm{H}, \mathrm{H}$ asler $\mathrm{G}$. Functional endoscopic sinus surgery: The messerklinger technique M osby 1991.

7. Stammberger H. Endoscopic endonasal surgery concepts in treatment of recurring rhinosinusitis (Part I). A natomic and pathophysiologic considerations. Otolaryngol Head N eck Surg 1986; $94: 143-47$.

8. Dawlaty EE. Inferior concha bullosa: A radiological and clinical rarity. Rhinology 1999;37:133-35.

9. Gupta A K, Gupta B, Gupta N, Tripathi N. Computerized tomography of paranasal sinuses: A roadmap to endoscopic surgery. Clin R hinol A n Int J 2012;5(1).
10. K eros $P$. Ü ber die praktische B edeutung der Niveauunterschiede der lamina cribrosa des ethmoids. Z Laryngol Rhinol Otol 1962;41:808-13.

11. Congdon ED. The distribution and mode of origin of septa and walls of the sphenoid sinus. A nat Rec 1930;18:97.

12. Delano M C, Fun FY, Zinreich SJ. Relationship of the optic nerve to the posterior paranasal sinuses: A CT anatomic study. A m J Neuroradiol 1996;17:669-75.

13. N itinavakarn B, Thanaviratananich S, Sangsilp N. A natomical variations of the lateral nasal wall and paranasal sinuses: A CT study for endoscopic sinus surgery (ESS) in Thai patients. J Med A ssoc Thai 2005;88(6):763-68.

14. Kainz J, Stammberger H. Danger areas of the posterior rhinobasis: A n endoscopic and anatomical-surgical study. A cta Otolaryngol (Stockh) 1992;112:852-61.

15. Sheetal D, Devan PP, M anjunath $P$, M artin P, Satish K umar K, Sreekantha, Satish TG, et al. CT PNS: Do we really require before fess? J Clin Diag Res 2011; 5(2):179-81.

16. B ent JP, Cuiltysiller C, K uhn FA. The frontal cell as a cause of frontal-sinus obstruction. Am J Rhinol 1994;8:185-91.

17. Wormald PJ. Endoscopic sinus surgery: A natomy, threedimensional reconstruction, and surgical technique. Thieme Medical Publishers N ew Y ork 2005.

18. W ormald PJ. The axillary flap approach to the frontal recess. L aryngoscope 2002;112:494-99.

19. W ormald PJ, Chan SZX. Surgical techniques for the removal of frontal recess cells obstructing the frontal ostium. A m J R hinol 2003; $17: 221-26$.

\section{ABOUT THE AUTHORS}

\section{Ashok K Gupta (Corresponding Author)}

Professor and Head, Department of Otolaryngology and Head and Neck Surgery (U nit II), Postgraduate Institute of M edical E ducation and Research, Chandigarh, India, Phone: +91-9814198850, e-mail: drashokpgi@ hotmail.com

\section{Sandeep Bansal}

Assistant Professor, Department of Otolaryngology and Head and Neck Surgery (U nit II), Postgraduate Institute of M edical Education and Research, Chandigarh, India

\section{Daisy Sahini}

Professor and Head, D epartment of A natomy, Postgraduate I nstitute of M edical Education and Research, Chandigarh, India 